\title{
Thermoelectric Power Studies Cu-Cd Ferrites
}

\author{
K. Rama Krishna ${ }^{1}$, K. Vijaya Kumar ${ }^{2}$, C. Abraham Lincoln ${ }^{3}$, D. Ravinder ${ }^{4}$ \\ ${ }^{1}$ Department of Physics, Malla Reddy College of Engineering \& Technology, Hyderabad, India; ${ }^{2}$ Department of Physics, College of \\ Engineering, Jawaharlal Nehru Technological University Hyderabad, Hyderabad, India; ${ }^{3}$ Department of Chemistry, P. G. College of \\ Science, Osmania University, Hyderabad, India; ${ }^{4}$ Department of Physics, P. G. College Of Science, Osmania University, Hyderabad, \\ India. \\ Email: ravindergupta28@rediffmail.com,dachepalliravindergupta@gmail.com
}

Received June $30^{\text {th }}, 2011$; revised August $2^{\text {nd }}, 2011$; accepted August $10^{\text {th }}, 2011$

\begin{abstract}
Thermoelectric Power Studies of Cadmium Substituted Copper Ferrites of various compositions were investigated from room temperature to well beyond the curie temperature by differential method. The Seebeck coefficient is negative for all compositions showing that these ferrites behave as n-type semi conductors. Plots of Seebeck coefficient verses temperature shows maximum at Curie temperature. On the basis of these results an explanation for the conduction mechanism in $\mathrm{Cu}-\mathrm{Cd}$ mixed ferrites is suggested.
\end{abstract}

Keywords: Cu-Cd Ferrites; Seebeck Coefficient; Hopping Mechanism; Curie Temperature

\section{Introduction}

Hall effect and Thermoelectric power studies are widely used in the interpretation of the conduction mechanism in semiconductors. The interpretation of Hall effect results in straight forward and it gives precise results. However in the case of low mobility semiconductors such as ferrites, it is sometimes difficult to measure the Hall Effect. In such cases the thermoelectric measurement is the only alternative. More ever, the measurement of thermo e.m.f. is simple and its sign gives vital information about the type of conduction in semi conductors i.e. whether they are n-type or p-type.

As per the present authors knowledge no information is available on thermoelectric power studies of mixed $\mathrm{Cu}-$ $\mathrm{Cd}$ ferrites in the literature. Moreover, there is need for thorough study of thermo electric power studies of Cadmium substituted Copper ferrites as a function of composition and temperature. The results of such study are presented in this communication.

\section{Experimental}

Mixed $\mathrm{Cu}-\mathrm{Cd}$ ferrites having the compositional formula $\mathrm{Cu}_{1-\mathrm{x}} \mathrm{Cd}_{\mathrm{x}} \mathrm{Fe}_{2} \mathrm{O}_{4}$ (where $\mathrm{x}=0.2,0.4,0.6$ and 0.8 ) were prepared by double sintering technique.

The Seebeck coefficients were measured by differenttial method [1] from room temperature to well beyond the Curie temperature. The temperature gradient across the sample was measured using two pairs of copper constant thermo couples. The sample was mounted on top of two well separated copper blocks with silver paint. The temperature difference between two ends of sample was kept at $10 \mathrm{~K}$ throughout the measured temperature range. To eliminate the effects of the reference loads, the absolute thermo electric power of subtracted from the measured thermoelectric voltage. A Keithley 181 nano volt meter was used for the voltage measurements.

Thermoelectric power or Seebeck coefficient $S$ was calculated using the relation $\mathrm{S}=\Delta \mathrm{E} / \Delta \mathrm{T}$ where $\Delta \mathrm{E}$ is thermo e.m.f. produced across the sample due to the temperature difference $\Delta \mathrm{T}$.

\section{Results and Discussion}

$\mathrm{X}$-ray diffraction pattern for all mixed $\mathrm{Cu}-\mathrm{Cd}$ ferrites have been obtained by using $\mathrm{CuK} \alpha$ radiation of RigakuDmaxII X-ray diffractometer conformed the spinel formation. The lattice parameters of different composition have been calculated using the values of d-spacing. Figure 1 shows the variation of lattice parameter with the cadmium content. It can be seen from the figure that the lattice parameter increased with the increase in Cadmium content. A similar increase in lattice parameter with composition was also observed by Bharti et al. in $\mathrm{Mg}-\mathrm{Zn}$ ferrites [2] and the case of Ni-Mg ferrites [3] by John Birchmas et al.

The values of Seebeck coefficient (S) at $310 \mathrm{~K}$ computed from the measured values of thermo e.m.f which are given in Table 1. It can be seen from the Table that the values of Seebeck coefficient (S) continuously increases from -845 to $-1490 \mu \mathrm{V} / \mathrm{K}$ with the increase of cadmium 


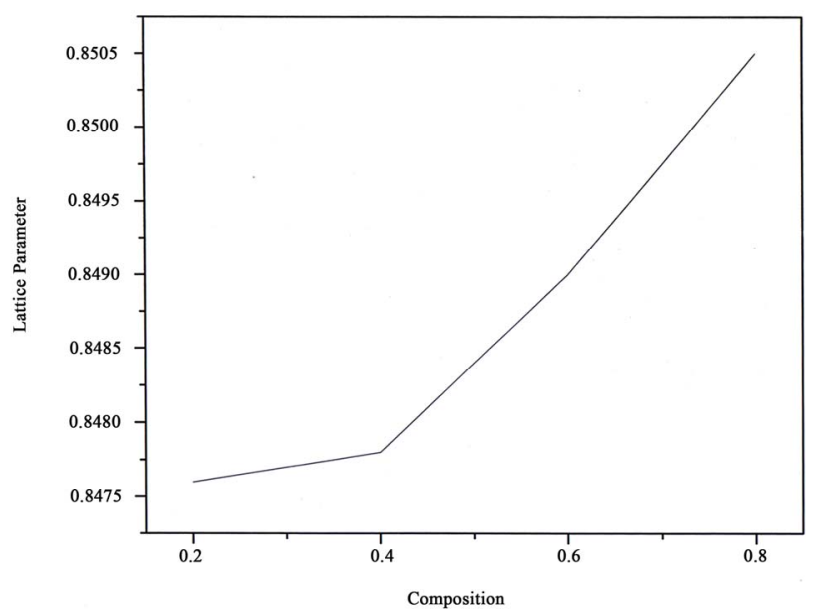

Figure 1. Variation of lattice parameter with composition.

Table 1. Seebeck coefficient transition temperature and Curie temperature data for $\mathrm{Cu}_{1-\mathrm{X}} \mathrm{Cd}_{\mathrm{X}} \mathrm{Fe}_{2} \mathrm{O}_{4}$ ferrite.

\begin{tabular}{|c|c|c|c|}
\hline S. No. & Ferrite & $\begin{array}{c}\text { Seebeck } \\
\text { Coefficient }(\mu \mathrm{V} / \mathrm{K})\end{array}$ & $\begin{array}{c}\text { Seebeck } \\
\text { Coefficient transition } \\
\text { Temperature } \mathrm{T}_{\mathrm{S}}(\mathrm{K})\end{array}$ \\
\hline 1 & $\mathrm{Cu}_{0.8} \mathrm{Cd}_{0.2} \mathrm{Fe}_{2} \mathrm{O}_{4}$ & -845 & 700 \\
\hline 2 & $\mathrm{Cu}_{0.6} \mathrm{Cd}_{0.4} \mathrm{Fe}_{2} \mathrm{O}_{4}$ & -1130 & 682 \\
\hline 3 & $\mathrm{Cu}_{0.4} \mathrm{Cd}_{0.6} \mathrm{Fe}_{2} \mathrm{O}_{4}$ & -1278 & 610 \\
\hline 4 & $\mathrm{Cu}_{0.2} \mathrm{Cd}_{0.8} \mathrm{Fe}_{2} 0_{4}$ & -1490 & 404 \\
\hline
\end{tabular}

content Among all the ferrites the specimen with composition $\mathrm{Cu}_{0.2} \mathrm{Cd}_{0.8} \mathrm{Fe}_{2} \mathrm{O}_{4}$ has the highest value of Seebeck coefficient. It can also be seen from the table that the sign of Seebeck coefficient [S] is negative for all Cadmium substituted Copper ferrites. On the basis of its negative sign the ferrites under investigation have been classified as n-type semiconductors. The conduction mechanisms in these ferrites are due to hopping of electrons from $\mathrm{Fe}^{2+}$ to $\mathrm{Fe}^{3+}$ ions [4].

$$
\mathrm{Fe}^{3+}+\mathrm{e}^{-} \Leftrightarrow \mathrm{Fe}^{2+}
$$

The variation of thermoelectric power (S) with temperature is as shown in Figures 2-5. It can be seen from the figures that the values of thermoelectric power for all $\mathrm{Cu}-\mathrm{Cd}$ ferrites increase with increasing temperature up to a certain temperature, which is designated as $\mathrm{T}_{\mathrm{S}}[\mathrm{K}]$. However beyond this temperature the value of $(\mathrm{S})$ starts to decrease with increasing temperature. The negative value of thermoelectric power found over the entire temperature range studied that the majority charge carriers are electrons. A similar thermo electric power with the temperature was observed in [5-8].

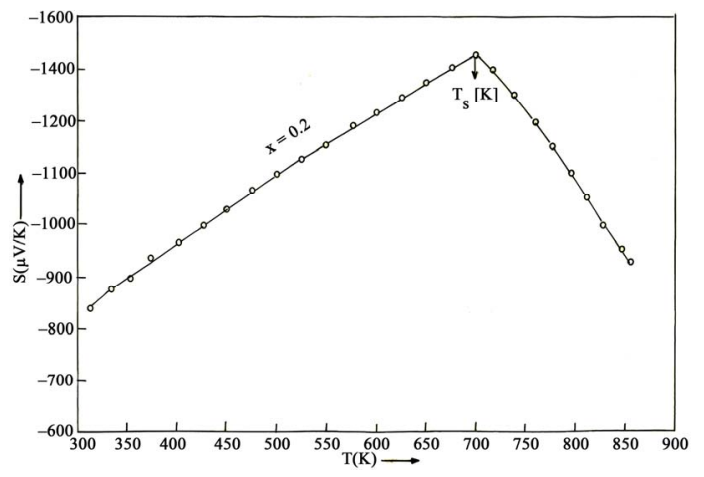

Figure 2. Variation of Seebeck coefficient with temperature for $\mathrm{X}=0.2$ composition.

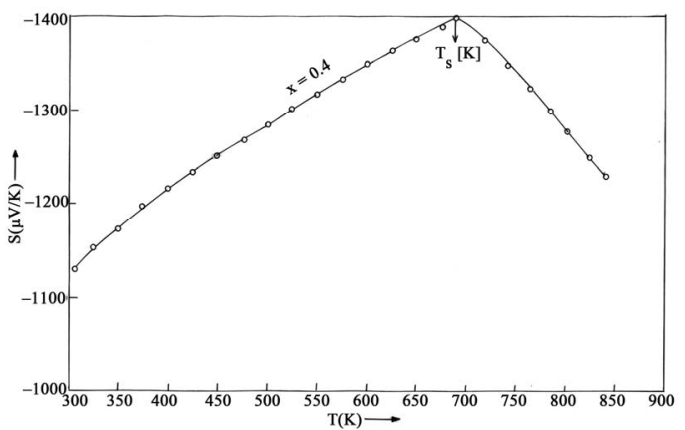

Figure 3. Variation of Seebeck coefficient with temperature for $\mathrm{X}=0.4$ composition.

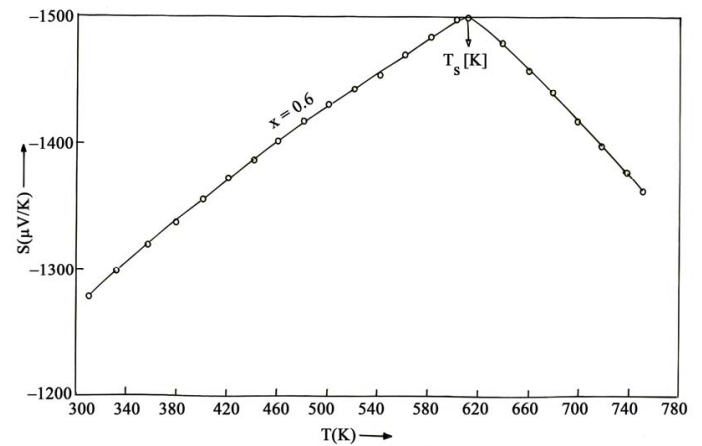

Figure 4. Variation of Seebeck coefficient with temperature for $\mathrm{X}=\mathbf{0 . 6}$ composition.

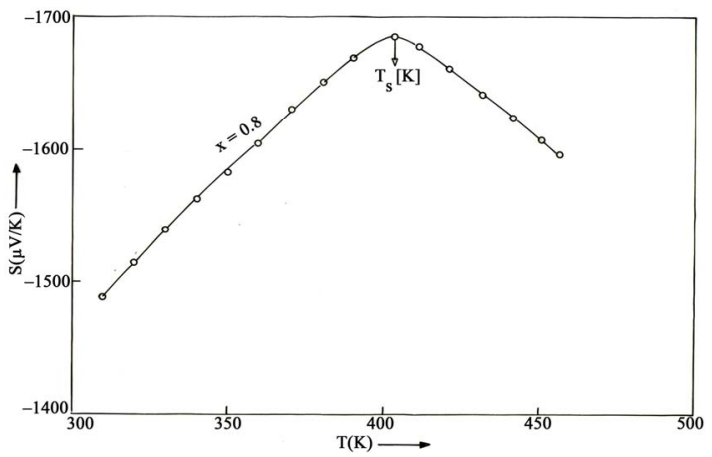

Figure 5. Variation of Seebeck coefficient with temperature for $X=0.8$ composition. 


\section{REFERENCES}

[1] Z. Simsa, "Distribution of Cations and Phase Transition in Ferrite $\mathrm{Cu}_{0.5} \mathrm{Fe}_{2.5} \mathrm{O}_{4}$,'IEEE Transactions on Magnetics, Vol. 5, No. 3, 1969, pp. 592-595. doi:10.1109/TMAG.1969.1066483

[2] D. C. Bharti, K. Mukherjee and S. B. Majunidr, "Wet Chemical Synthesis and Gas Sensing Properties of Magnesium Zinc Ferrite Nano-Particles," Materials Chemistry and Physics, Vol. 120, No. 2-3, 2010, pp. 509-517. doi:10.1016/j.matchemphys.2009.11.050

[3] L. J. Berchmans, R. K. Selvan, P. N. S. Kumar and C. O. Augustin, "Structural and Electrical Properties of $\mathrm{Ni}_{1-\mathrm{x}}{ }^{-}$ $\mathrm{Mg}_{\mathrm{x}} \mathrm{Fe}_{2} \mathrm{O}_{4}$ Synthesized by Citrate gel Process," Journal of Magnetism and Magnetic Materials, Vol. 279, No. 1, pp. 103-110.

[4] L. J. Berchmans, R. K. Selvan, P. N. S. Kumar and C. O. Augustin, "Structural and Electrical Properties of $\mathrm{Ni}_{1-\mathrm{x}}{ }^{-}$ $\mathrm{Mg}_{\mathrm{x}} \mathrm{Fe}_{2} \mathrm{O}_{4}$ Synthesized by Citrate Gel Process," Journal of Magnetism and Magnetic Materials, Vol. 279, No. 1, 2004, pp. 103-110.

[5] R. G. West and A. C. Blankership, "Magnetic Properties of Dense Lithium Ferrites," Journal of the American Ceramic Society, Vol. 50, No. 7, 1967, pp. 343-349. doi:10.1111/j.1151-2916.1967.tb15129.x

[6] T. Gron, S. Mazur, H. Duba, J. Krok-Kowalski and E. Maciazek, "Effect of Double Exchange on Thermoelectric Power of $\mathrm{Cu}_{\mathrm{x}} \mathrm{Co}_{\mathrm{y}} \mathrm{Cr}_{\mathrm{z}} \mathrm{Se}_{4}$," Journal of Alloys and Compounds, Vol. 467, No. 1-2, 2009. pp. 112-119. doi:10.1016/i.jallcom.2008.01.001

[7] P. P. Hankare, V. T. Vandir, U. B. Svankpal, L. V. Gavali, R. Sasikala and I. S. Mulla, "Synthesis and Characterization of Nano Crystalline Ti-Substituted Zn Ferrite," Journal of Alloys and Compounds, Vol. 509, No. 5, 2009, pp. 2160-2163. doi:10.1016/j.jallcom.2010.10.173

[8] T. E. Whal, N. Salerno, Y. GProjkova, K. A. Mizza and S. Mazen, "The Electrical Conductivity and Thermoelectric Power of Lithium Ferrite in the Vicinity of the OrderDisorder Transition Temperature," Philosophical Magazine Part B, Vol. 53, No. 5, 1986, pp. L107-L113.

[9] Md A. Malik, V. D. Reddy, P. V. Reddy, D. R. Sagar and P. Kishan, "Charge Transport in Mg-Ge Mixed Ferrites," Modern Physics Letters, Vol. 13, 1994, p. 947. 